УДК 343.3

\title{
С.А. Стяюкина
}

\section{НЕЗАКОННЫЙ ОБОРОТ ОФИЦИАЛЬНЫХ ДОКУМЕНТОВ: УГОЛОВНО-ПРАВОВОЙ АСПЕКТ}

В статье рассматриваются вопросы уголовной ответственности за посягательства на порядок официального документооборота. Подробно анализируются понятие и признаки документа и официального документа как предметов уголовно-правовой охраны. Предложены критерии отграничения документа и официального документа, а также классификации документов. Особое внимание уделено анализу изменений, внесенных в Уголовный кодекс РФ летом 2019 года в статью 327 УК РФ, предусматривающую ответственность за подделку, изготовление или оборот поддельных документов, государственных наград, штампов, печатей или бланков. В статье детально исследуются объективные признаки составов преступлений, посягающих на официальные документы, к которым относятся приобретение, сбыт, похищение, уничтожение, повреждение, сокрытие, а также подделка официальных документов, сбыт поддельных официальных документов и их использование. Рассмотрены вопросы субъективной стороны данных преступлений. Также в статье уделено внимание проблемам отграничения использования заведомо поддельных официальных документов, ответственность за которое предусмотрена в часть 4 статьи 327 УК РФ от преступлений, где использование поддельных документов выступает способом совершения преступления, таких как мошенничество, незаконное получение кредита и др. Высказаны предложения о целесообразности внесения изменений в ряд статей Уголовного кодекса РФ, предусматривающих ответственность за посягательство на официальный документооборот.

Ключевые слова: официальный документ, удостоверение, важный личный документ, подделка официальных документов, приобретение, сбыт, похищение, уничтожение, повреждение официальных документов, использование документов.

DOI: $10.35634 / 2412-9593-2019-29-6-892-898$

Официальный документооборот является частью управленческой деятельности государства. Для эффективной деятельности органов государства и осуществления функций контроля и надзора существует огромный массив предметов управленческой деятельности, к которым относятся официальные документы, штампы, печати и бланки. Любая управленческая деятельность государства сопряжена с оформлением различного рода документов, в которых фиксируются решения, принимаемые органами государственной власти и местного самоуправления. Общественная опасность преступлений, посягающих на порядок официального документооборота, связана с тем, что в предметах управленческой деятельности фиксируются и подтверждаются различные права и обязанности лиц, которым они выданы, государство фиксирует и контролирует через официальный документооборот статус лиц, получивших документы.

Несмотря на длительную историю развития уголовного законодательства, предусматривающего ответственность за незаконный оборот официальных документов, как в теории, так и на практике возникают проблемы определения тех или иных предметов управленческой деятельности, отсутствует единообразный подход к определению официального документа, появляются новые виды официальных документов. Кроме того, необходимо отметить, что быстрыми темпами развивается система электронного документооборота, что зачастую создает трудности в правовой оценке посягательств на документы, созданные в виде электрических сигналов.

В качестве предмета уголовно-правовой охраны до изменений, внесенных в Уголовный кодекс РФ, выступали не все документы, а только официальные, среди которых отдельно выделялись паспорт, удостоверение и иной важный личный документ. Но в июле 2019 законодатель в ч. 5 ст. 327 УК РФ предусмотрел ответственность за использование заведомо подложного документа.

Таким образом, на сегодняшний день законодатель выделяет несколько видов документов, дифференцируя уголовную ответственность в зависимости от вида документа. На основе анализа норм уголовного законодательства, предусматривающего ответственность за посягательство на порядок официального документооборота, можно выделить несколько разновидностей предметов уголовно-правовой охраны: документ; официальный документ; паспорт; удостоверение, предоставляющее права или освобождающее от обязанностей; иной важный личный документ. В отдельную группу 
Незаконный оборот официальных документов: уголовно-правовой аспект

документов следует выделить акцизные марки, специальные марки, знаки соответствия (ч. 3 ст. 325 , ст. 327.1 УК РФ), а также документы на лекарственные средства и медицинские изделия и упаковки на лекарственные средства и медицинские изделия (ст. 327.2 УК РФ).

Существует несколько определений документа, содержащихся в различных нормативноправовых актах. Законодательное определение содержится в Федеральном законе от 29.12.94 № 77 Ф3 «Об обязательном экземпляре документов», где сказано, что документ - это «материальный носитель с зафиксированной на нем в любой форме информацией в виде текста, звукозаписи, изображения и (или) их сочетания, который имеет реквизиты, позволяющие его идентифицировать, и предназначен для передачи во времени и в пространстве в целях общественного использования и хранения» ${ }^{1}$. Также понятие документа можно встретить в Постановлении Правительства РФ от 15 июня 2009 г. № 477 «Об утверждении Правил делопроизводства в федеральных органах исполнительной власти», где предлагается следующее определение: «"Документ" - официальный документ, созданный государственным органом, органом местного самоуправления, юридическим или физическим лицом, оформленный в установленном порядке и включенный в документооборот федерального органа исполнительной власти» ${ }^{2}$. Во втором определении документ и официальный документ рассматриваются как тождественные понятия.

Исходя из законодательного определения документа можно выделить его признаки. Во-первых, это формальная определенность, то есть документ должен иметь материальный носитель, который может быть в любом виде (бумажный, графический, электронный). В качестве второго признака можно выделить его информационное содержание: документ должен содержать какие-либо сведения, сообщения в любом виде (текстовый, звуковой, визуальный). В-третьих, документ должен иметь реквизиты, позволяющие его идентифицировать (бланки, штампы, печати, подписи). Четвертым признаком указана цель его создания - общественное использование и хранение.

Надо сказать, что под это определение подпадает достаточно большой массив различного рода документов, исходящих от огромного количества субъектов, начиная со справок в бассейн и заканчивая сертификатами и различного рода документами, выдаваемыми различными структурами как государственными, муниципальными, так и коммерческими.

Законодатель в ч. 5 ст. 327 УК РФ предусмотрел ответственность за использование заведомо подложного документа. По нашему мнению, ставить под уголовно-правовую охрану любой документ не представляется оправданным и целесообразным. Исходя из того, что видовым объектом рассматриваемых преступлений является порядок управления, когда речь идет об исполнительнораспорядительной деятельности государства, одним из инструментов которой выступают официальные документы, устанавливать уголовную ответственность за использование подложного документа, не относящегося к числу официальных, нет необходимости, поскольку это ничем не обосновано.

Уголовный кодекс РФ предусматривает ответственность за незаконный оборот официальных документов, в частности, за их незаконное приобретение, сбыт, похищение, уничтожение, повреждение, сокрытие и подделку, а также за использование и сбыт поддельных официальных документов. Однако следует отметить, что легального определения официального документа не существует. Данное понятие вырабатывается доктриной уголовного права на основе анализа правоприменительной практики. Представляется, что наиболее удобным будет выделение признаков, которыми должен обладать официальный документ, и в зависимости от наличия или отсутствия данных признаков относить тот или иной документ к числу официальных.

На наш взгляд, к признакам официального документа следует отнести следующие. Во-первых, обязательно должны предьявляться требования к оформлению: бланк, печать, штамп, реквизиты, подписи. Как указывается в Постановлении Правительства РФ от 15 июня 2009 г. № 477 «Об утверждении Правил делопроизводства в федеральных органах исполнительной власти», реквизитами документов, создаваемых в процессе деятельности федерального органа исполнительной власти, являются: а) Государственный герб Российской Федерации; б) наименование федерального органа исполнительной власти; в) наименование структурного подразделения федерального органа исполнительной власти; г) наименование должности; д) справочные данные о федеральном органе исполнитель-

\footnotetext{
${ }^{1}$ Федеральный закон от 29.12.94 №Ф3 - 77 «Об обязательном экземпляре документов» // СПС «Гарант».

${ }^{2}$ Постановление Правительства РФ от 15 июня 2009 г. № 477 «Об утверждении Правил делопроизводства в федеральных органах исполнительной власти» // СПС «Гарант».
} 
ной власти; е) наименование вида документа; ж) дата документа; з) регистрационный номер документа; и) ссылка на регистрационный номер и дату входящего документа; к) место составления (издания) документа; л) гриф ограничения доступа к документу; м) адресат; н) гриф утверждения документа; о) указания по исполнению документа (резолюция); п) заголовок к тексту; р) текст документа; с) отметка о контроле; т) отметка о приложении; у) подпись; ф) отметка об электронной подписи; х) гриф согласования документа; ц) виза; ч) печать; ш) отметка о заверении копии; щ) отметка об исполнителе; э) отметка об исполнении документа и направлении его в дело; ю) отметка о поступлении документа; я) ссылка на документ ${ }^{3}$.

Во-вторых, официальный документ должен предоставлять права либо освобождать от обязанностей, определять статус лица, которому он выдан. Официальный документ должен являться своеобразным юридическим фактом, с которым закон связывает возникновение, изменение или прекращение правоотношений. Это содержательный признак официального документа, позволяющий отграничивать его от иных документов, охрана которых не предусмотрена Уголовным кодексом РФ.

Третьим признаком выступает то, что официальный документ должен входить в систему регистрации и учета. Это необходимо, во-первых, для контроля и учета выданных документов, во-вторых, для восстановления утраченных документов.

Четвертый признак связан с источником происхождения. Официальные документы должны исходить от органов государственной власти, органов местного самоуправления, государственных и муниципальных учреждений, Вооруженных сил РФ и иных организаций, которым государство делегировало это право. К таким организациям могут относиться и коммерческие организации, деятельность которых по выдаче официальных документов контролируется государством. Контроль осуществляется в виде лицензирования, проверок соответствия их деятельности государственным стандартам, учета выдаваемых документов.

Из общего числа официальных документов, законодатель выделяет паспорт, важный личный документ и удостоверение, предоставляющее права или освобождающее от обязанностей, ответственность за похищение которых, предусмотрена в ч. 2 ст. 325 УК РФ, а за подделку в ч. 2 ст. 327 УК РФ. Таким образом, законодатель дифференцирует ответственность в зависимости от вида документа.

В соответствии с Постановлением Правительства РФ от 08.07.1997 г. «Об утверждении Положения о паспорте гражданина Российской Федерации, образца бланка и описания паспорта гражданина Российской Федерации» паспорт «является основным документом, удостоверяющим личность гражданина Российской Федерации на территории Российской Федерации» ${ }^{4}$. Кроме паспорта гражданина Российской Федерации Федеральный закон от 16.08.1996 №114-Ф3 «О порядке выезда из Российской Федерации и въезда в Российскую Федерацию» в качестве документов, удостоверяющими личность гражданина Российской Федерации, по которым граждане Российской Федерации осуществляют выезд из Российской Федерации и въезд в Российскую Федерацию, признаются паспорт, дипломатический паспорт, служебный паспорт ${ }^{5}$. Все они выступают предметом преступления.

К важным личным документам следует относить документы, определяющие статус физического лица, наделяющие его какими-либо правами или обязанностями, закрепляющими его полномочия (водительское удостоверение, студенческий билет, трудовая книжка и т. д.). Еще законодатель выделяет в качестве отдельного предмета уголовно-правовой охраны удостоверение, предоставляющее права или освобождающее от обязанностей, к которому следует относить пенсионное удостоверение, удостоверение сотрудника правоохранительных органов, военный билет и др. В целях единообразного применения закона предлагаем унифицировать эти два вида документов и оставить в качестве признака преступлений только важный личный документ.

Обращаясь к проблеме объективной стороны преступлений, посягающих на официальные документы, следует отметить, что Уголовный кодекс РФ предусматривает различного рода деяния, совершаемые с официальными документами в различных статьях УК РФ, что не всегда удобно и целесообразно.

\footnotetext{
${ }^{3}$ Постановление Правительства РФ от 15 июня 2009 г. № 477 «Об утверждении Правил делопроизводства в федеральных органах исполнительной власти» // СПС «Гарант».

${ }^{4}$ Постановлением Правительства РФ от 08.07.1997 г. «Об утверждении Положения о паспорте гражданина Российской Федерации, образца бланка и описания паспорта гражданина Российской Федерации» // СПС «Гарант».

${ }^{5}$ Федеральный закон от 16.08.1996 № 114-Ф3 «О порядке выезда из Российской Федерации и въезда в Российскую Федерацию» // СПС «Гарант».
} 
В ст. 324 УК РФ предусматривается ответственность за незаконное приобретение и сбыт официальных документов. Под приобретение традиционно понимается любой способ получения, как возмездный, так и безвозмездный, не предусмотренный законом (покупка, получение в дар, обмен, присвоение найденного), за исключением похищения, так как ответственность за похищение официальных документов предусмотрена в ст. 325 УК РФ. Законный способ приобретения связывается с процедурой выдачи подобного рода документов органами государственной власти, органами местного самоуправления, иными организациями, обладающими правом выдачи соответствующих документов.

Сбыт предполагает любой способ отчуждения (дарение, продажа). Следует отметить, что официальные документы не являются собственностью лица, которым они выданы, на них не распространяются правомочия собственника и владелец документов не может их отчуждать. Причем также не имеет значения, какой официальный документ приобретается или сбывается, будь то паспорт или любой другой документ.

Ответственность за похищение, уничтожение, повреждение и сокрытие официальных документов, относящихся к организациям, предусмотрена в ч. 1 ст. 325 УК Р $\Phi^{6}$, а за похищение паспорта или другого важного документа - в ч. 2 ст. 325 УК РФ $\Phi^{7}$. Кроме того, в качестве обязательного признака субъективной стороны похищения, повреждения, уничтожения и сокрытия официального документа выступает корыстная или иная личная заинтересованность. Что касается похищения паспорта или иного важного личного документа, то законодатель не выделяет конструктивных признаков субъективной стороны. Необходимо отметить, что ч. 2 ст. 325 УК РФ не является, как это обычно принято в Уголовном кодексе РФ, квалифицированным составом преступления. Статья 325 УК РФ включает три части, объединенных в рамках одной статьи, каждая из которых предусматривает самостоятельный состав преступления. Таким образом, мы приходим к выводу, что уголовной ответственности за уничтожение, повреждение и сокрытие паспорта или другого важного личного документа не предусмотрено.

Похищение представляет собой противоправное изъятие документов у лиц, владеющих ими законно, любым способом (тайно, открыто, с помощью обмана) и является одним из способов незаконного приобретения. Таким образом, не представляется обоснованным выделять в рамках самостоятельного состава преступления похищение документов.

Уничтожение предполагает приведение документов в состояние, непригодное для использования по назначению, при невозможности восстановления. Повреждение заключается в нарушении целостности документа при сохранении возможности восстановления. Сокрытие официальных документов выражается в их утаивании от законных владельцев либо субъектов, управомоченных эти документы проверять, изымать.

Не совсем ясна позиция законодателя относительно дифференциации ответственности в зависимости от вида официального документа и признаков объективной стороны. Представляется целесообразным объединить в рамках одного состава преступления все действия, совершаемые с официальным документом, и предусмотреть уголовную ответственность за незаконные приобретение, сбыт, уничтожение, повреждение и сокрытие официальных документов, независимо от вида документа.

Традиционно в качестве самостоятельного состава преступления предусматривается подделка официальных документов, сбыт поддельных официальных документов и их использование. Но в июле 2019 г. в ст. 327 УК РФ в качестве признаков объективной стороны были добавлены приобретение, хранение, перевозка поддельных официальных документов с целью их использования или сбыта.

Подделка официальных документов может выражаться в двух формах: полная подделка и частичная. При полной подделке изготавливается полностью новый поддельный документ с использованием, например, похищенных бланков, множительной, копировальной техники. Что касается частичной подделки, то она выражается во внесении в настоящий официальный документ изменений, искажающих его действительное содержание. Обязательным признаком выступает то, что содержание документа должно измениться, например, вносятся заведомо ложные сведения или вытравливается часть текста, содержащего важную информацию. Если изменения не касаются сути документа и не являются ложными, то подделкой это не является. Документ в результате подделки должен изменить свое содержание. Следует отметить, что обязательным признаком подделки выступает цель - использование заведомо подложного документа.

\footnotetext{
${ }^{6}$ Уголовный кодекс РФ // СПС «Гарант».

${ }^{7}$ Там же.
} 
Сбыт заведомо подложного документа предполагает любой способ его отчуждения, к которым могут относиться продажа, дарение, обмен и другие возможные варианты отчуждения, как возмездные, так и безвозмездные.

Законодатель дифференцировал ответственность за подделку официальных документов и сбыт поддельных официальных документов в зависимости от вида документа. В качестве квалифицирующего признака на сегодняшний день выступает подделка паспорта или удостоверения гражданина, предоставляющего права или освобождающего от обязанности. Следует отметить, что как подделка официального документа, так и подделка паспорта или удостоверения относятся к преступлениям небольшой тяжести, что свидетельствует о нецелесообразности выделения подделки паспорта или удостоверения в качестве квалифицирующего состава. Если учесть, что, по данным Судебного Департамента при Верховном Суде РФ, к лишению свободы до одного года за подделку официальных документов в 2018 г. было всего привлечено 15 человек, за все остальные преступления были назначены наказания, не связанные с лишением свободы (штраф, обязательные работы).

Новеллой уголовного законодательства стало установление ответственности за приобретение, хранение и перевозку в целях использования или сбыта заведомо поддельных паспорта гражданина, удостоверения или иного официального документа, предоставляющего права или освобождающего от обязанностей ${ }^{8}$.

Следует отметить, что ч. 3 ст. 327 УК РФ, предусматривающая ответственность за «приобретение, хранение, перевозку в целях использования или сбыта либо использование заведомо поддельных паспорта гражданина, удостоверения или иного официального документа, предоставляющего права или освобождающего от обязанностей, штампов, печатей или бланков» ${ }^{9}$, не является особо квалифицированным составом применительно к чч. 1 и 2 ст. 327 УК РФ. Здесь также в одной статье объединены три самостоятельных преступления, различающихся по признакам объективной и субъективной сторон. Законодатель в силу единства объекта посягательства и предмета преступных действий объединил в рамках одной статьи разные составы преступлений.

Традиционно под приобретение в нормах уголовного права понимается любой способ их получения независимо от возмездности или безвозмездности. В данном случае к приобретению будет относиться и похищение поддельных документов.

Хранение предполагает совершение действий, обеспечивающих сохранность поддельных документов, в том числе в помещениях, тайниках.

Перевозка означает транспортировку поддельных документов любым видом транспорта с целью их перемещения из одного места в другое.

В этой части указывается еще на такое деяние, как использование заведомо поддельных паспорта гражданина, удостоверения или иного официального документа ${ }^{10}$. Под использование понимается предъявление, предоставление поддельного документа по назначению. В зависимости от вида документа предполагаются и разные варианты их использования. Если речь идет о водительском удостоверении, то использование предполагает его предъявление сотрудникам ГИБДД при управлении транспортным средством, если речь идет о дипломе, то использование означает его предъявление при трудоустройстве и т.д. Как правило, речь идет о лицах, которые сами документы не подделывают, а лишь используют приобретенные поддельные официальные документы. Причем квалификация по данному преступлению возможна только в случаях, если в действиях лица, использующего поддельный официальный документ, отсутствуют признаки других составов преступлений, в частности, мошенничества или уклонения от уплаты налогов. Если поддельный официальный документ выступает в качестве средства совершения другого преступления, то ответственность за его использование по ч. 3 ст. 327 УК РФ не наступает.

Состав рассматриваемого преступления является формальным и преступление считается оконченным с момента совершения любого из действий, перечисленных в диспозиции. Кроме того, мы можем сказать, что он относится к числу сложных составов с альтернативным описанием признаков объективной стороны. Преступление считается оконченным с момента совершения одного из действий, описанных в диспозиции статьи, но и совершение всех действий не образует множественности преступлений.

\footnotetext{
${ }^{8}$ Уголовный кодекс РФ // СПС «Гарант».

${ }^{9}$ Там же.

${ }^{10}$ Уголовный кодекс РФ // СПС «Гарант».
} 
Обращаясь к проблеме множественности преступлений применительно к данному составу преступления, следует отметить, что на практике зачастую возникают проблемы квалификации подделки официальных документов и их сбыта в случаях, когда подделываются и сбываются несколько документов. С одной стороны, можно говорить о продолжаемом преступлении, если умыслом лица охватывалось изготовление нескольких поддельных документов или предполагался сбыт нескольких поддельных документов. С другой стороны, сбыт осуществляется разным лицам, и в официальный документооборот вводятся различные документы. Представляется, что если умыслом лица охватывалась подделка сразу нескольких официальных документов или сбыт различных документов, то целесообразнее рассматривать данные действия как единичное продолжаемое преступление. Если подделка осуществляется в разное время и умысел каждый раз возникает самостоятельно, то следует квалифицировать по совокупности преступлений.

В качестве обязательного признака субъективной стороны приобретения, хранения и перевозки поддельных официальных документов законодатель указывает на цель этих действий - использование поддельных официальных документов либо их сбыт. Таким образом, если лицо приобретает или хранит, либо перевозит поддельный документ, не собираясь его использовать, то состава преступления не будет. Здесь правоприменитель столкнется с проблемами доказывания цели приобретения, и тем более - хранения или перевозки.

Представляется, что криминализация приобретения, хранения и перевозки поддельных официальных документов не совсем обоснована. Во-первых, вызывает сомнение общественная опасность данных деяний. Обращаясь к объекту рассматриваемых преступлений, следует отметить, что сам факт приобретения или хранения, а тем более перевозки поддельных документов не нарушает официального документооборота. Пока поддельные документы не поступили в обращение, никаких неблагоприятных изменений в государственном регулировании документооборота не происходит.

Во-вторых, быстрыми темпами развивается система электронного документооборота, и в ближайшем будущем большая часть документов будет представлена в электронном виде, что гораздо удобнее и безопаснее. Таким образом сама собой отпадет проблема хранения, перевозки официальных документов и их приобретения. Также возникнет вопрос о возможности их подделки. Скорее всего речь будет идти о неправомерном доступе к компьютерной информации (ст. 272 УК РФ) и подделке официальных документов.

Часть 4 ст. 327 УК РФ предусматривает квалифицированный состав двух самостоятельных преступлений: подделка официального документа, предоставляющего права или освобождающего от обязанностей, в целях его использования или сбыт такого документа и приобретение, хранение, перевозка в целях использования или сбыта либо использование заведомо поддельных паспорта гражданина, удостоверения или иного официального документа, предоставляющего права или освобождающего от обязанностей, штампов, печатей или бланков ${ }^{11}$.

В качестве квалифицирующего признака двух составов выступает цель совершения вышеуказанных действий - это «скрыть другое преступление или облегчить его совершение» ${ }^{12}$. Данный признак является традиционным для рассматриваемой группы преступлений. Очень часто подделка официальных документов является приготовлением к мошенничеству и его видам (ст. 159, 159,1, 159.2, 159.5 УК РФ), незаконному получению кредита (ст. 176 УК РФ), фиктивной регистрации граждан РФ по месту пребывания или по месту жительства в жилом помещении в Российской Федерации и фиктивной регистрация иностранного гражданина или лица без гражданства по месту жительства в жилом помещении в Российской Федерации (ст. 322.2 УК РФ), фиктивной постановки на учет иностранного гражданина или лица без гражданства по месту пребывания в Российской Федерации (ст. 322.3 УК РФ) и другим. Поддельный документ в таких случаях определяет способ совершения преступлений.

Здесь необходимо остановиться на проблеме отграничения использования заведомо поддельного официального документа, ответственность за которое предусмотрена ч. 3 ст. 327 УК РФ и ч. 5 ст. 327 УК РФ от преступлений, где использование поддельного документа выступает способом совершения преступления.

\footnotetext{
${ }^{11}$ Уголовный кодекс РФ// СПС «Гарант».

12 Там же.
} 
Если поддельный официальный документ используется для совершения другого преступления лицом, не подделывавшим этот документ, то ответственность наступает только за то преступление, для совершения которого лицо использовало документ (без совокупности с чч. 3, 5 ст. 327 УК РФ). В случаях когда лицо само подделало официальный документ и использовало его для совершения другого преступления, уголовная ответственность наступает по совокупности преступлений по ч. 4 ст. 327 УК РФ и за то преступление, в котором поддельный официальный документ использовался для его совершения (например, мошенничество при получении выплат - ст. 159.2 УК РФ).

Еще одной новеллой уголовного законодательства явилось установление в ч. 5 ст. 327 УК РФ уголовной ответственности за «использование заведомо подложного документа» ${ }^{13}$. Исходя из рассмотренного выше определения документа подобные деяния в лучшем случае могут рассматриваться как административные правонарушения. Нельзя привлекать к уголовной ответственности за предъявление поддельной справки в бассейн или школу. Предметом уголовно-правовой охраны должны выступать только официальные документы, отвечающие всем требованиям, связанные с определением статуса лиц, которым они выданы, оборот которых контролируется государством.

В заключение следует отметить, что официальный документооборот - это часть управленческой деятельности государства и сфера уголовно-правового регулирования обращения документов, она должна касаться только той части, которая связана с исполнительно-распорядительной деятельностью государства. Кроме того, учитывая, что динамично развивается сфера электронного документооборота, необходимо кардинально пересмотреть структуру и содержание уголовно-правовых норм, предусматривающих ответственность за посягательства на официальные документы.

Поступила в редакцию 21.09.2019

Стяжкина Светлана Александровна, кандидат юридических наук, доцент

ФГБОУ ВО «Удмуртский государственный университет»

426034, Россия, г. Ижевск, ул. Университетская, 1 (корп. 4)

\title{
S.A. Styazhkina
}

\section{ILLEGAL TURNOVER OF OFFICIAL DOCUMENTS: CRIMINAL LEGAL ASPECT}

\author{
DOI: $10.35634 / 2412-9593-2019-29-6-892-898$
}

The article discusses the issues of criminal liability for encroachments on the procedure of official document circulation. The concept and features of a document and an official document as subjects of criminal law protection are analyzed in detail. Criteria are proposed for distinguishing between a document and an official document, as well as the classification of documents. Particular attention is paid to the analysis of amendments to Article 327 of the Criminal Code of the Russian Federation, made in the summer of 2019, which provide for responsibility for the falsification, production or circulation of fake documents, state awards, stamps, seals or letterheads. The article examines in detail the objective features of the elements of crimes encroaching on official documents, which include the acquisition, sale, stealing, destruction, damage, concealment, as well as forgery of official documents, the sale of fake official documents and their use. The issues of the subjective side of these crimes are considered. The article also focuses on the problems of delimiting the use of obviously fake official documents, the responsibility for which is provided for in paragraph 4 of Article 327 of the Criminal Code of the Russian Federation from crimes, where the use of fake documents acts as a means of committing a crime, such as fraud, illegal obtaining a loan, etc. Suggestions are made on the appropriateness amending a number of articles of the Criminal Code of the Russian Federation, providing for liability for encroachment on official documents.

Keywords: official document, certificate, important personal document, falsification of official documents, acquisition, sale, stealing, destruction, damage to official documents, use of documents.

Styazhkina S.A., Candidate of Law, Associate Professor

Udmurt State University

Universitetskaya st., 1/4, Izhevsk, Russia, 426034

\footnotetext{
${ }^{13}$ Уголовный кодекс РФ // СПС «Гарант».
} 